\title{
La piel a partir de la experimentación del bioarte. Uso de microorganismos en propuestas artísticas
}

\author{
María Gabriela Punín Burneo \\ Universidad Técnica Particular de Loja \\ mgpuninx@utpl.edu.ec
}

\author{
Karina Monteros Cueva \\ Universidad Técnica Particular de Loja \\ kmonteros@utpl.edu.ec
}

\begin{abstract}
Resumen
En el arte contemporáneo, es posible vislumbrar múltiples manifestaciones creativas en donde la piel posee un rol como punto central de la obra. En el bioarte, la piel se convierte en una herramienta de representación que permite generar nuevos significados y valores interpretativos. El presente trabajo versa sobre los resultados de una experimentación con el microorganismo "Medusomyces gisevi", modificando sus condiciones físicas y químicas para conseguir una materia prima que permite representar la piel, dentro de propuestas artísticas basadas en las huellas que el dolor y el sufrimiento pueden dejar en los seres humanos.
\end{abstract}

\section{Palabras clave}

Bioarte, piel, herida, memoria, microorganismo.

\section{A pele da experimentação de bioart. Uso de microrganismos em propostas artísticas}

\begin{abstract}
Resumo
$\mathrm{Na}$ arte contemporânea múltiplas manifestações criativas são vistas onde a pele tem um papel como ponto central do trabalho. Na bioarte, a pele torna-se uma ferramenta de representação que permite produzir novos significados e valores interpretativos. Este trabalho experimenta com o microorganismo "Medusomyces gisevi", modificando suas condições físico-químicas para obter uma matéria-prima que permitisse representar a pele, em propostas artísticas cujo tema foi baseado nos traços que a dor e o sofrimento podem sair em humanos.
\end{abstract}

\section{Palavras-chave}

Bioarte, pele, ferida, memoria, microrganismo.

Skin from the experimentation of bio-art. The use of microorganisms for artistic proposals

\footnotetext{
Abstract

In contemporary art, we can identify multiple creative manifestations where skin has a central role in the work. In bio-art, skin becomes a tool of representation that enables the production of new meanings and interpretative values. The present work
} 
deals with the results of an experimentation with the microorganism "Medusomyces gisevi", modifying its physical and chemical conditions to obtain a raw material that represents the skin. This project is situated within the framework of artistic proposals based on the remnants that pain and suffering can leave in human beings.

\section{Keywords}

Bio-art, skin, wound, memory, microorganism. 
Los avances de la ciencia han permitido que el arte tenga nuevos planteamientos, siendo uno de los más importantes el del uso y la representación del cuerpo usando la biotecnología, a través de la experimentación con tejidos vivos (Carreño, 2012: 36). De este modo nace el bioarte, como resultado de una fusión entre arte, ciencia y tecnología (Kac, 2005: 304) que le permite al artista desarrollar su producción con un lenguaje reflexivo y sobre una base biotecnológica, generando la oportunidad de romper arquetipos y demostrar que estas ciencias no son del todo distintas: cada una lleva una parte de la otra (Lattanzi, 2013: 22).

De acuerdo con Daniel López del Rincón y Lourdes Cirlot (2013), los trabajos de bioarte se pueden clasificar en dos grandes tendencias análogas: biomedial y biotemática. La tendencia biomedial comprende la obra de George Gesert, Joe Davis y Peter Gerwin Hoffmann, mientras que la biotemática incluye la obra de Kevin Clarke, Nell Tenhaaf, Pam Skelton y Dennis Ashbaugh. Sus investigaciones son diversas: en gran parte de ellas, se conjugan la ciencia y el arte, aunque en algunos casos incluyen sistemas de telecomunicación óptica, sistemas robóticos y de microfabricación, así como la construcción y aplicaciones de rayo electrón y sistemas de teleoperador láser. La investigación que presentamos en estas líneas es de carácter biomedial, comprendiendo lo medial en relación al medio biológico material, pues incorpora técnicas y procedimientos en los cuales se estudia el cultivo de microorganismos a partir de conceptos y pruebas de laboratorio, además de acusar la aparición de una tendencia de carácter crítico y activista que propone una nueva manera de enlazar con la biotecnología.

Entre los iniciadores del bioarte se encuentran Joe Davis y George Gesert, quienes se despojaron de las técnicas tradicionales del arte representativo mimético para demostrar que objetos insignificantes y cotidianos podían transformarse, mezclarse y mutar para ser expuestos como obras de arte (Gesert, 2012: 233). Por su parte, Stelarc, Marta de Menezes y Gilberto Esparza resignifican estéticamente los objetos a través de ensayos de laboratorio, modificando sus condiciones para convertirlos en obra artística cuya base es el uso de las ciencias biológicas. La obra de Stelarc se caracteriza por la utilización de su propio cuerpo como soporte de sus obras: "intervenciones quirúrgicas, injertos artificiales y la añadidura de miembros prostéticos son algunos de los elementos que dan forma a una estética de lo artificial" (AAL, 2016, 27 de agosto); conduciendo al espectador a preguntarse por qué los seres humanos nos constituimos de esta manera, así como a considerar la posibilidad de cambiar nuestros cuerpos para adaptarnos a las condiciones cambiantes del mundo. Marta Menezes, en Nature?, centra su creatividad en mariposas sujetas a transformaciones fenotípicas (Quintais, 2009: 97); seres que, por sus colores, formas y simetrías, inspiran feminidad, elegancia y delicadeza, dentro de una propuesta despojada de un deseo de perpetuidad. Gilberto Esparza (2015), con su obra Nómadas, hace una reflexión sobre los entornos modificados por la actividad humana y las consecuencias sociales y ambientales que pueden tener en la vida de organismos que tienen que adaptarse o desaparecer. 
Teniendo en cuenta estas evoluciones, el objetivo de esta investigación ha sido desarrollar una propuesta de representación de la piel basada en el bioarte a través de la experimentación con materiales biológicos, con el ánimo de producir piezas artísticas que puedan llegar a transgredir lo cotidiano y previsible. En el arte contemporáneo, la fusión entre arte y tecnología hace imposible establecer normas estéticas válidas, abriendo un abanico de oportunidades para la multidisciplinariedad. El presente artículo posee tres momentos: el primero consiste en un desarrollo teórico que sustenta un trabajo artístico con la piel y sus cicatrices; el segundo se relaciona con la elaboración de una materia prima similar a la piel, mediante una experimentación en laboratorio; el tercero, con la aplicación del material obtenido en una propuesta artística basada en las relaciones entre piel, memoria y cicatrices.

\section{Piel, memoria y heridas}

Si se habla del lenguaje como medio de expresión o comunicación, es preciso enfatizar que cada lenguaje es rico en metáforas que describen la gama de reacciones o de expresiones. Las personas pueden comunicarse a través de las expresiones para transmitir sentimientos y sensaciones. En materia de arte, la piel se puede convertir en un lienzo como una manifestación atemporal y crítica, pero depende del receptor y de la creatividad del artista el mensaje que se pueda transmitir a través de esta manipulación. En este sentido, hay cuerpos que no comunican y otros que pueden transferir la intención del hablante; la piel no puede ser una realidad lingüística, pero tampoco puede ser solo una materialidad, pues entre ambas dimensiones se estrechan lazos de interdependencia.

Considerando que la piel comunica en cada momento, ya sea en situaciones cotidianas o excepcionales y premeditadas, puede llegar a ser estrictamente un lenguaje discursivo; hay actos que hablan por sí solos y son capaces de causar una herida, que, a la vez, puede ser un signo, ya que el ser humano es lingüísticamente vulnerable. La piel es considerada para la propuesta artística a desarrollar como un elemento que permite transmitir un pensamiento, es decir, como una respuesta a un yo interno y social o a una forma personal que se desprende de lo social.

De acuerdo con Martínez, "la piel como superficie simbólica" puede representar "la pieza clave del proceso de transculturación, elemento esencial de conexión, relieve único que constituye el cuerpo y sus constelaciones; es decir, zona erógena, de contacto físico y ritual donde se producen múltiples metamorfosis" (2011: 234). La piel se considera como un espacio de inscripción donde la memoria fija un sinfín de acontecimientos que dan lugar a la emergencia de otra piel, que, a manera de vestimenta, protege al cuerpo, como ocurre también con la piel pintada; de este modo, la piel no se percibe ni desnuda ni expuesta. Más bien, se convierte en "una página a doble cara" donde lo escrito a nivel de la superficie representa lo inscrito en el interior del cuerpo. 


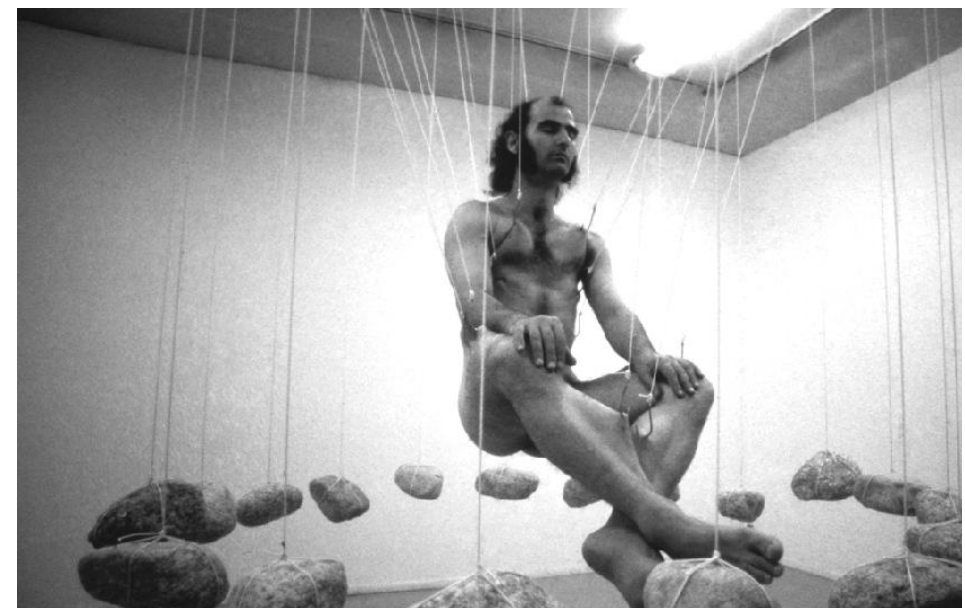

Figura 1. Stelarc (1980), "Sitting/Swaying: Event for Rock Suspension".

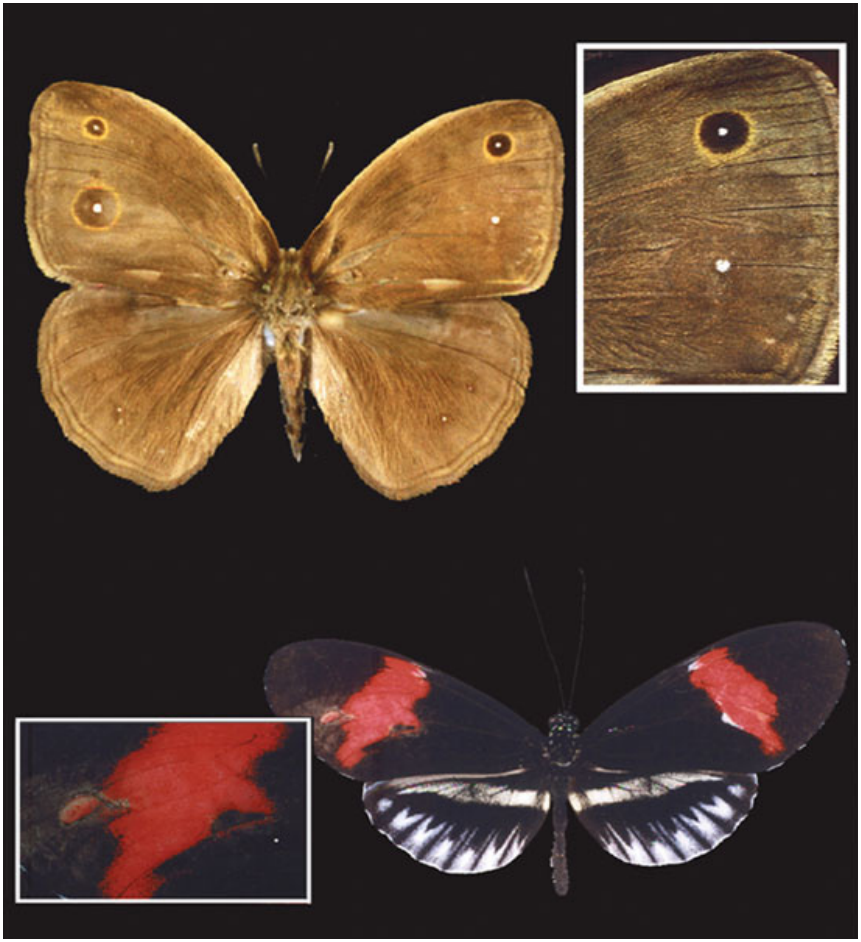

Figura 2. Marta Menezes, (1999), Nature?. 
Las huellas que deja el sufrimiento en el cuerpo necesitan convertirse en objeto científico que se puede explicar por leyes universales, pero esto requiere de una serie de información "extra” no contenida en ellas. Para Aristóteles, "todo cuerpo natural que posee la vida debe ser sustancia y sustancia de tipo compuesto" (Salgado, 2012: 7). Debido a que todo cuerpo tiene materia y forma que proporciona vida dando una vitalidad en otra dimensión, al tener sensaciones, es necesario preguntarnos: ¿tiene la vida un valor intrínseco, diferente del valor de no-vida? ¿Es la vida diferente de la no-vida, en el sentido de que es un sujeto más que un objeto? Heidegger menciona que "rechaza la cuestión de vida misma biológica" (1999: 14). La vida tiene un valor por ser la integridad del ser, el ser en esencia, su dimensión trascendental; tiene su diferencia la vida con la no-vida porque, biológica (cuerpo-soma) y psicológicamente (psique), dependen el uno del otro y, además, de lo afectivo. A partir de la valoración de ese cuerpo con esa biología es como se percibe la realidad de las cosas. La artista Sandra Martínez Rossi, en relación a la fenomenología, cita a Maurice Merleau-Ponty: "no tenemos un cuerpo, sino que 'somos cuerpo', en tanto que percibimos el mundo a través de él, en tanto que nos distanciamos del saber objetivo para sumergirnos en las vivencias del cuerpo" (en Martínez, 2011: 48).

Al exponer el cuerpo como una superficie simbólica, se le quiere mostrar como una superficie poblada de significados: un lugar de pensamientos, emociones y, en general, de la vida, desde lo fisiológico hasta la complejidad de procesos y acciones. El cuerpo es la constitución de la identidad humana y, al mismo tiempo, la imagen misma del ser humano; por tanto, sin él, el ser humano no podría ser entendido como persona. A la concepción de cuerpo surgida en la modernidad, "Hegel le proporciona una conciencia histórica; Marx le agrega una conciencia social y Freud le da un inconsciente, un pasado y un sexo" (Mejía, 2005: 23).

Por otra parte, el cuerpo, la vida, la bios son lenguajes y requieren necesariamente de un espectador; esta última presencia es parte de la obra, porque sin él o ella, la obra está incompleta. Así, se considera, para esta propuesta, la representación de la piel como símbolo de una comunicación no verbal, que opera un acto al transmitir sensaciones, conductas y, en ocasiones, palabras no emitidas. Este lenguaje se hace comprensible en y a través de la memoria corporal, que guarda toda la historia de un individuo desde que se encuentra en el vientre materno. La memoria se construye y da sentido a un ser y a la sociedad porque está cargada de valor y de necesidades sociales enmarcadas en visiones del mundo, así como del pasado, el presente y el futuro del ser humano. Para Linda Benglis (1969), la memoria corporal es parte de la genética, pues registra y conserva información de la cual no se es consciente. Hay necesidades, emociones reprimidas, temores y aspiraciones íntimas que encuentran un lugar en la piel, para anidarse luego en la memoria corporal, de modo que se puede considerar a la piel como "el lugar donde la memoria se encuentra inmediatamente accesible" (De Certeau, 1997: 1). Llevar la memoria en el cuerpo implica que la persona se reconoce en las prác- 
ticas ejercidas en la rutina. La memoria-cuerpo es reactualización del pasado y del presente, entendida como un proceso de utilización de lo heredado y de las experiencias adquiridas conforme al requerimiento presente.

Ligado al concepto de memoria, los conceptos de herida y cicatriz representan un punto de partida para la reflexión sobre una serie de ideas y distinciones fundamentales en relación con las nociones de "ser" y "ente", la "presencia" y lo "presente". Las heridas y cicatrices también se expresan en las prácticas cotidianas, incluyendo las actividades rutinarias de comer, cocinar, caminar o narrar. De acuerdo con Iván Mejía, las heridas, al ser el producto de una experiencia de dolor no simulado y un vínculo de proximidad con el cuerpo no imaginario que cambia, se deteriora y perece, resultan un elemento de trasgresión que desafía las convenciones sobre la función del cuerpo femenino como objeto sexual, símbolo espiritual y vehículo de fecundidad (2005: 45). Abordar la huella involucra referirse a recuerdos y olvidos, narrativas y actos, silencios y gestos. Estos significados que el espectador recibirá están constituidos por la historia propia de las heridas y cicatrices, pero, a la vez, por el significado de un acontecimiento que se construye con un nuevo sentido y se replantea a partir del dolor. La piel queda como recinto de memoria y de cada huella, de una historia. Esta revaloración del dolor remite al cuerpo a partir de una condición de vida que se renueva constantemente.

La piel, sea sencillamente materia lingüística o no, influye en el lenguaje de lo que se quiere decir, un lenguaje de cicatrices y heridas que pueden ser principio activo de significados; las heridas pueden romper el orden del cuerpo, pero, a la vez, exponen lo corporal que lo delimita y define como ser social. Evidenciar estas huellas son los pasos que constituyen el proceso creativo, que va de la decisión de hacerse presente al estar sumido en la ausencia e, incluso, que puede pasar del olvido a la represión. La piel, entonces, es el detonante para una construcción simbólica. Este lenguaje corporal tiene que dejar de expresar solamente belleza para transformarse en la herramienta de un lenguaje inédito de la época que sea capaz de hablar por sí mismo. Las propuestas corpóreas desarrolladas tienen como finalidad reflejar las ideas expuestas. Antes de presentarlas, expondremos el trabajo previo realizado para producir el símil de la piel.

\section{La piel en el laboratorio}

Buscando generar una piel artificial capaz de replicar el lenguaje de la piel humana real, la experimentación en laboratorio consistió en realizar múltiples caracterizaciones de Medusomyces gisevi, conocido en nuestra localidad como "hongo chino". Esta simbiosis se manipuló en el laboratorio alterando su ph, su temperatura y demás condiciones, buscando favorecer sus características para que sea un material moldeable. Con este fin, se identificaron molecularmente los diferentes microorganismos presentes en ella, estudiando su resistencia, flexibilidad y rugosidad. En forma paralela, se usaron diferentes tintes naturales para producir co- 
lores similares a la piel que pudieran conseguir una mayor resistencia al material como curtiente, para, finalmente, evaluar las propiedades físicas y mecánicas de la simbiosis y su expansión, al momento de aplicarla en piezas artísticas.

Dentro del trabajo de laboratorio se incluyeron estudios sobre los agentes externos e internos que pudieran afectar a la simbiosis en etapa de biopolímero, dando resultados negativos al momento de usarlo en creaciones artísticas. Se analizaron los productos auxiliares usados en el pre y el post tratamiento, el teñido, el acabado final, el nivel de impurezas y de contaminación por depósitos, así como la compatibilidad con los colorantes.

Para la obtención de la simbiosis hasta llegar al biopolímero se realizó una incisión al cuerpo principal, con cuidado para no lesionar ni al donante ni al receptor. Así, se debió separar cuidadosamente las capas de la simbiosis y trasladarlas a un frasco limpio con agua para su reproducción.

Se dejó una película de la simbiosis bañada con agua caliente a temperatura ambiente durante un día, en un recipiente cubierto con una doble capa de gasa limpia. En este tiempo se fertilizó con una solución de té sin azúcar en un recipiente de vidrio. Hasta ese momento, la simbiosis era muy susceptible a las influencias externas, de ahí la importancia de colocar la gasa para cubrirla. Para preparar el medio de crecimiento, se utilizó agua embotellada, por estar libre de bacterias; tras haber transcurrido el tiempo de reposo, se vertió la simbiosis en el medio de cultivo que debió estar lo suficientemente maduro. Luego de dos a tres días, se pudo observar en la superficie del líquido una nueva masa viscosa de piel transparente, que, sumergida en el agua, era casi invisible.

Una propiedad del biomaterial es el color. Para aplicarlo, se extrajo el líquido de la simbiosis cuando alcanzó un grosor de 3 a $5 \mathrm{~mm}$, que es cuando toma un color blanquecino al desprenderse de la madre. Este color lo adquiere cuando la simbiosis madre es pura y no tiene ningún tipo de contaminación, aunque, si esta simbiosis es contaminada y su color va oscureciendo, éste puede ser modificado con el uso de sal en grano y taninos .

En este proceso se emplearon colorantes naturales como el tinte de cochiniIla , un extracto de "inchi" y, opcionalmente, para efectos de experimentación, colorantes sintéticos como el solofenil en color azul y amarillo. Se realizaron dos mediciones, la primera en condiciones de humedad y la segunda cuando la masa estaba en estado seco. Con ello, se obtuvieron diferentes resultados de teñido.

Para la formulación del tinte cochinilla, se tomaron como referencia las pautas generales para el proceso de teñido artesanal con colorantes naturales propuestas por Martínez (2009: 20). En ellas se utilizó como mordiente el sulfato de aluminio y potasio (alumbre) y, como asistente, el tartrato ácido de potasio (crémor tártaro). La cantidad de dichas sustancias, así como de tinte, se calculó en función del peso de la celulosa bacteriana que se tiñó. 
Panambín. 7 Valparaíso dic. 2018 ISSN 0719-630X. 115-131. DOI:10.22370/panambi.2018.7.1176.

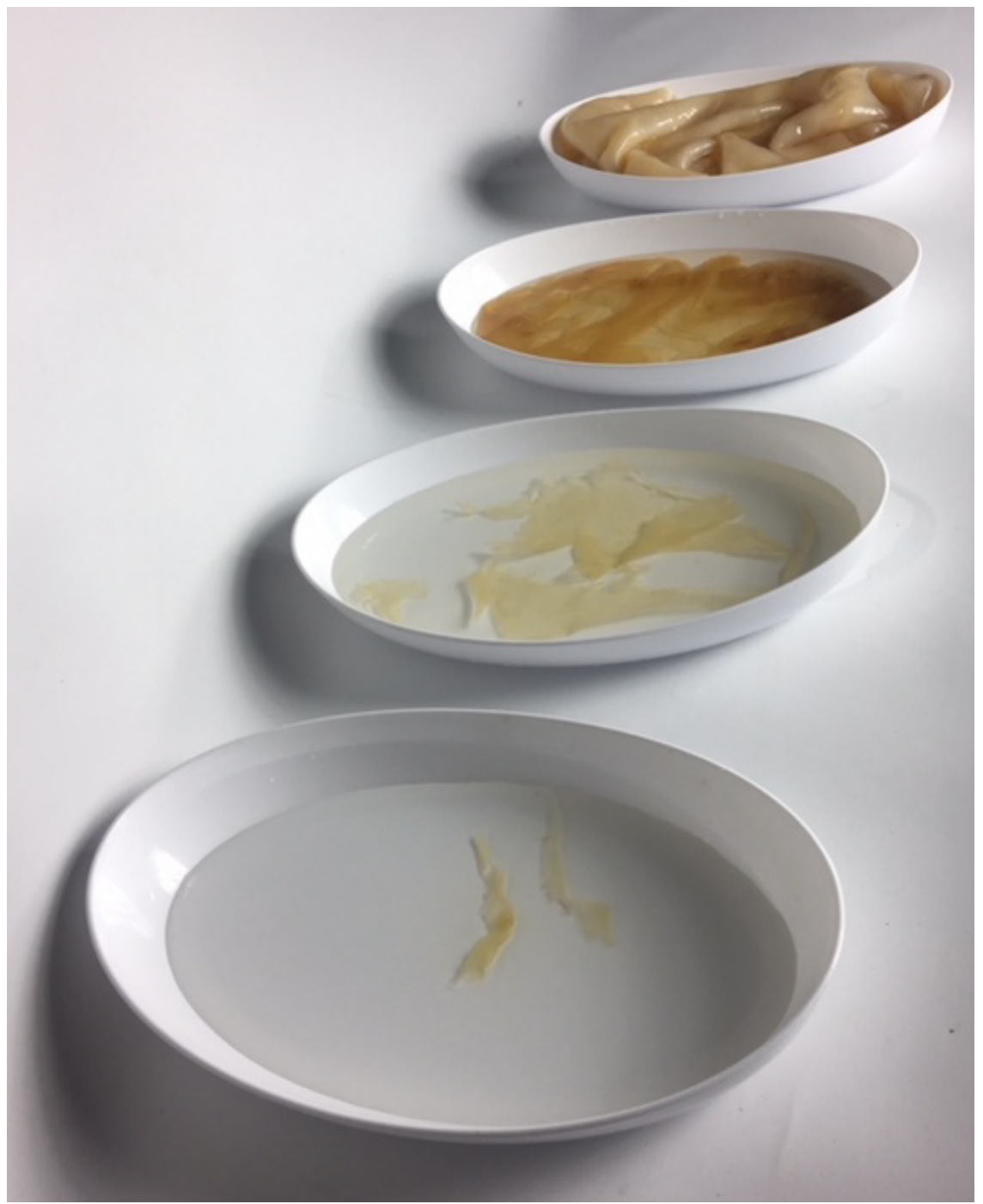

Figura 3. . Proceso de experimentación de la simbiosis al biopolímero. Fotografía de Gabriela Punin. 


\begin{tabular}{|l|l|l|}
\hline \multicolumn{3}{|c|}{ Cálculo y reporte de datos: Ensayo \#1 } \\
\hline $\begin{array}{l}\text { Peso de simbiosis mi- } \\
\text { crobiana seca }\end{array}$ & $1.63 \mathrm{gr}$. & $100 \%$ \\
\hline & $\mathrm{X} 25 \%$ & \\
& $\mathrm{X}=0,40 \mathrm{~g}$ & Cantidad de cochinilla a pesar \\
& $1.63 \mathrm{~g}$ & $100 \%$ \\
& $\times 10 \%$ & \\
& $\mathrm{X}=0,163 \mathrm{~g}$ & Cantidad de alumbre y crémor \\
\hline
\end{tabular}

Tabla 1. Formulación simbiosis, cochinilla, alumbre en sus cantidades.

La cantidad de agua que se utilizó también se determinó en función del peso; así, por cada $10 \mathrm{~g}$ de muestra se utilizaron $200 \mathrm{ml}$ de agua, pero, en forma opcional, se pueden utilizar $250 \mathrm{ml}$ por cada $15 \mathrm{~g}$ de muestra, usando proporcionalmente el agua respecto al peso real de la celulosa bacteriana. Cabe señalar que los resultados dependen del tamaño de la muestra: el peso de la muestra determinará la cantidad necesaria de agua para fijar el color de manera satisfactoria. Así, tenemos las siguientes proporciones:

\begin{tabular}{|l|l|l|}
\hline Simbiosis microbiana en masa & $200 \mathrm{ml}$ & $10 \mathrm{~g}$ \\
\hline & $\times 33,70 \mathrm{~g}$ & \\
& $\mathrm{X}=674 \mathrm{ml}$ & Cantidad de agua a utilizar \\
\hline
\end{tabular}

Tabla 2. Variación de proporciones de la formulación simbiosis más agua.

\begin{tabular}{|l|l|l|}
\hline Simbiosis microbiana seca & $200 \mathrm{ml}$ & $10 \mathrm{~g}$ \\
\hline & $\times 1,63 \mathrm{~g}$ & \\
& $\mathrm{X}=32,6 \mathrm{ml}$ & Cantidad de agua a utilizar \\
\hline
\end{tabular}

Tabla 3. Variación de proporciones de la formulación simbiosis más agua.

Análisis similares se realizaron utilizando el inchi y el solofenil amarillo y azul, arrojando diferentes resultados.

Para obtener un biopolímero de buenas condiciones, es necesario saber que la simbiosis con la que se trabaja es susceptible de alteración con el uso de productos químicos, por cuanto inhiben el crecimiento de la materia prima. Debido a ello, es necesario evitar la presencia de impurezas en el ambiente líquido en el cual se desarrolla la simbiosis.

El color no puede medirse directamente, pues depende de la fuente luminosa, el objeto mismo y el observador. Sin embargo, entre las muestras analizadas se escogió la coloración que dio el tinte de la cochinilla, por las flexibilidades que presenta y porque no altera la calidad del material por sus componentes naturales. 


\begin{tabular}{|l|c|c|}
\hline \multicolumn{1}{|c|}{ Tintes } & Celulosa en masa & Celulosa seca \\
\hline Solofenil azul & $0.46 \mathrm{~g}$ & $0.030 \mathrm{~g}$ \\
Solofenil amarillo & $0.32 \mathrm{~g}$ & $0.006 \mathrm{~g}$ \\
Cochinilla & $8.43 \mathrm{~g}$ & $0.40 \mathrm{~g}$ \\
Extracto de planta shuar & $30 \mathrm{ml}$ & $20 \mathrm{ml}$ \\
\hline
\end{tabular}

Tabla 4. Cantidad de tinte utilizado en los diferentes tipos de colorantes tanto en celulosa bacteriana seca como en masa.

Los extractos naturales obtuvieron mejor compatibilidad con la simbiosis que con los productos químicos, que pueden alterar la flexibilidad del biopolímero. Adicionalmente al color, los resultados preliminares de pruebas de función del tiempo permitieron sugerir lo que es óptimo para el producto.

\begin{tabular}{|l|c|c|c|c|c|c|c|}
\hline Resistencia/días & Inicial & 3 días & 4 días & 5 días & 6 días & 9 días & 14 días \\
\hline Muestra 1 & 3,31 & 2,93 & 2,88 & 2,83 & 2,80 & 2,60 & $2,62-2,60$ \\
Muestra 2 & 3,24 & 2,95 & 2,82 & 2.75 & 2,73 & 2,51 & 2,46 \\
Muestra 3 & 2,43 & 2,44 & 2,47 & 2,45 & 2,47 & 2,41 & 2,54 \\
Control & 4,49 & 2,91 & 2,84 & 2,76 & 2,73 & 2,52 & 2,43 \\
\hline
\end{tabular}

Tabla 5. Resultados de las pruebas preliminares.

De lo expuesto, se optó por trabajar con la muestra número 1, por la resistencia que mostró, y con el tinte de cochinilla, el cual dio mejores resultados en cuanto a la similitud del color de la piel.

\section{"Manos heridas" y "Otra mirada al cuerpo"}

Entre más avanzan la ciencia y la tecnología, más complejo se torna el estudio del cuerpo y la piel, motivo por el cual el bioarte resulta ser el lenguaje más idóneo para repensar el cuerpo, repensar la biología y los conceptos con los que se puede referir al cuerpo. En esta búsqueda interpretativa, resulta prioritario que los motivos escogidos, como son la cicatriz, la herida o la marca corporal, sean percibidos integralmente y no sólo como elementos efímeros o permanentes del cuerpo, pues, de lo contrario, nunca se podría acceder a ellos en su metamorfosis simbólica y las explicaciones permanecerían en la superficie. Para ello, la simbiosis elaborada en el laboratorio fue probada y posteriormente validada en la representación de heridas, de manera de convertir al cuerpo en un tipo de conciencia y denuncia, pues "el lenguaje corporal contiene la ciencia misma del hombre, que tiende a renovar las fuerzas del inconsciente con la memoria de lo humano, lo sagrado, el espíritu, la psique, con el dolor y la muerte para restituir la conciencia" (Pane, 2003: 15). 
De acuerdo con Benítez, "hacer un nuevo arte, como hacer una revolución en ciencia, significa hacer visibles contenidos, conceptos y no solo descubrir nuevas formas" (Benítez, 2013: 25). El bioarte es la pauta de esta exploración artística, para que la muestra no quede en una mera aplicación del material, sino en poder mostrar, a través de la obra, los nuevos significados del dolor, las heridas y la memoria. La naturaleza objetiva, tanto en ciencia como en cultura, no puede existir de forma separada de la construcción social, como un ambiente reflexivo para que la obra pueda actuar, además, como denuncia.

En la obra denominada "Manos heridas" (2014) se representó una fina herida de sangre sobre la simbiosis del microorganismo. Todos los cuerpos tienen huellas y dejan una marca en diversos ámbitos privilegiados, como las imágenes, las palabras, las metáforas del cuerpo. Esta marca se intentó expresar de una forma narrativa, en cuanto el ser construye un sentido narrativo del pasado, con una memoria que se formula en un cuerpo; es decir, el ser humano siente y se comunica narrativamente. La marca en la obra se consiguió no sólo mediante la similitud del material a la piel, sino también con la aplicación de conceptos básicos de composición. Esta pieza es parte de un conjunto que complementa el proceso de transformación de la simbiosis en obra de arte, permitiendo hacer algunas analogías con piezas posteriores.

A manera de denuncia, se puede preguntar: ¿se encuentran huellas en el cuerpo, en las secuelas de un rastro? El pasado siempre deja una huella en el cuerpo: el paso de los años, las enfermedades, los accidentes, que son difíciles de eliminar o revertir, van dejando huellas de una manera simbólica o perpetua; con la intención de evidenciarlo es que se plasma la herida en esta obra. A través de la memoria que inscriben las heridas en nuestro cuerpo, se pretendió que el espectador se involucrara en la obra y en las circunstancias que le llevaron a incidir en su cuerpo; pero ahora con esperanza de dar nuevos significados al cuerpo, para que adquiera un nuevo sentido. Lo que motivó la aplicación de este concepto en el cuerpo fue el deseo de querer sanar interiormente tanto la experiencia de dolor como sus consecuencias, accediendo a su significado para transformarlo a partir de nuevos elementos.

La piel guarda la intencionalidad corporal a partir de los momentos en que el lenguaje y cuerpo no coinciden; esta ha sido la premisa de este trabajo, pues es ahí, cuando se abre el espacio para la experimentación y la implementación de nuevas formas de representar el arte, cuando el cuerpo se convierte en principio activo de nuevos significados.

Involucrar a la tecnología con el arte está dentro del concepto de bioarte. Es así como con la biotecnología o la genética se modifica y se abre una puerta a nuevas propuestas del cuerpo desde reflexiones que no se habían dado en otras décadas, como el uso de materiales biológicos con fines artísticos o la reflexión sobre las relaciones entre ciencia y arte como instrumento. Por ello, se podría asegurar que el cuerpo es un principio activo de resignificación. 


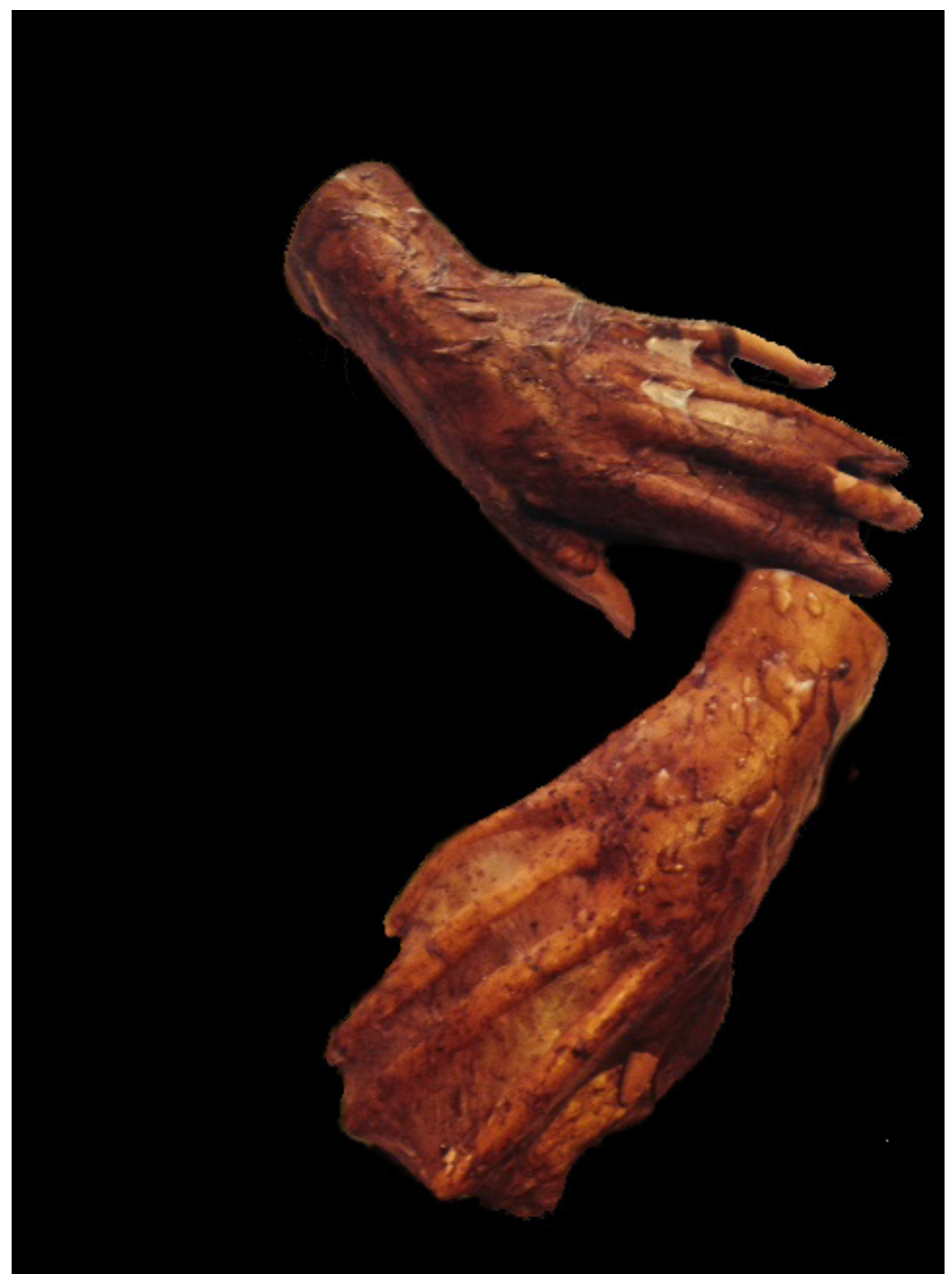

Figura 4. María Gabriela Punin (2014), "Manos heridas". 


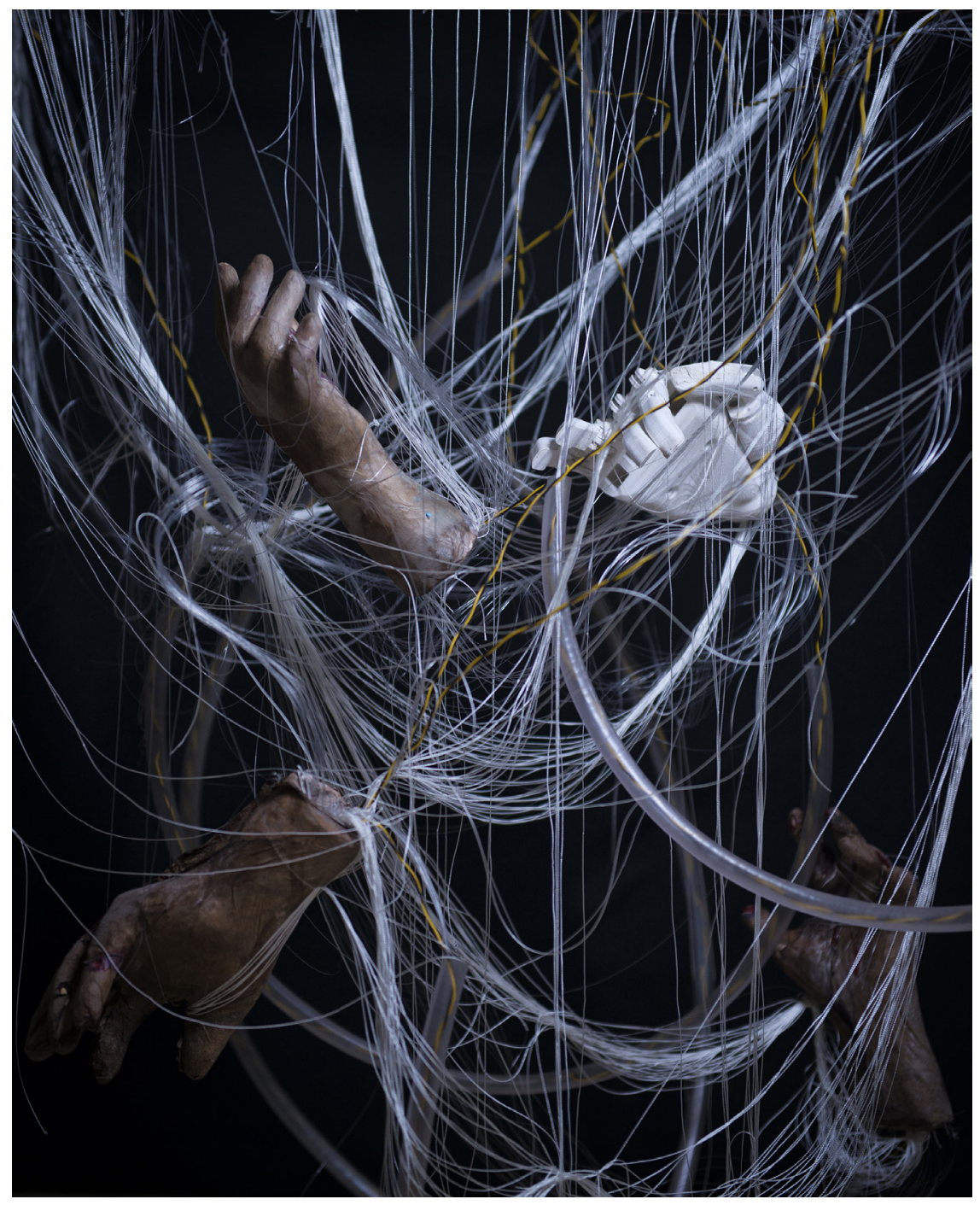

Figura 5. María Gabriela Punin, "Otra mirada al cuerpo". 
La segunda obra, denominada "Otra mirada al cuerpo", está constituida de varios elementos: cables, redes, manos robóticas y la representación de manos con el uso de la simbiosis. Esta obra representa los tejidos de un cuerpo actual y la tecnología que se puede incorporar intentando reflejar la interconexión entre el mundo actual modernizado y la naturaleza humana. Se manifiesta la manera en que el cuerpo se convierte en el lugar de intercambio, de conectividad y el proceso mediante el cual se transforma en interfaz para convertirse en una experiencia de lo inusual, donde el cuerpo biológico-orgánico pasa a ser un elemento extraño en un entorno de tecnología. La piel es un conjunto de experiencias sensibles que se despliegan e interactúan en un vínculo de sensaciones, de procesos de biología, de fisiología sometida a leyes de la naturaleza, como son la gravedad, la inercia y las leyes mecánicas. De esta manera, vemos que la piel puede ser infinita en su misma expresión y no tener límites de representación artística.

\section{Conclusiones}

A lo largo del presente trabajo se fueron evidenciando ciertos cambios debido al vínculo del arte con la ciencia en el estudio de una nueva tendencia de investigación, donde se considera al ser humano desde una cosmovisión real, tangible y, a la vez, espiritual e imaginaria. A partir de esta visión transgresora y creativa de los últimos cincuenta años hasta el momento actual, donde el mundo ha sido desafiado por grandes avances tecnológicos que van desde la ingeniería genética y molecular hasta la nanotecnología y la robótica, incluso se está promoviendo el desarrollo y la experimentación de vida artificial mediante el rejuvenecimiento celular. Esta investigación se inspira en dichos adelantos científicos para ir descubriendo nuevas técnicas en cuanto a la sobrevivencia de la bacteria, a la modificación de su textura, a su durabilidad y su consistencia como materia prima, lo que no tendría que ser visto como una amenaza, sino como un desafío dentro de las ciencias biológicas.

Durante la experimentación de este proceso estético, los conceptos de los cuales se partió, como son los bios, ciencia, arte, tecnología, vida, cuerpo, huellas, memoria y resignificación, junto a los ensayos de laboratorio del proceso de transformación de la simbiosis, permitieron desarrollar sobre este recurso estético la muestra artística, en sus diferentes representaciones. El haber desarrollado una propuesta dentro del campo del bioarte como proceso creativo permitió evidenciar que la experimentación es primordial para la producción artística. Esto dio la posibilidad de evaluar, desde un pensamiento crítico, la transformación de la simbiosis en una obra artística, realizar experimentaciones para simular la piel y, a la vez, representar un cuerpo que pudiera transmitir un mensaje, por un lado. Por otro lado, esto condujo a la artista a ser sensible con la responsabilidad que conlleva la alteración, la modificación o el uso de un organismo vivo; es decir, a tener presente que debe reflexionar en los límites de lo permitido, de manera de no transgredir la ética. 
El bioarte ha permitido analizar y construir una plataforma para la reflexión sobre las relaciones entre arte y ciencia y, especialmente, con la biología, pudiendo definirse el arte como una práctica artística de investigación, debido a que posee aportes en cuanto a la aplicación de los procesos creativos para llegar a constituir la obra. Por otro lado, el bioarte engloba proyectos artísticos que conciben a la investigación como un conjunto de procesos incluyentes, transversales y heterogéneos para la elaboración de nuevos productos con bases biológicas que puedan ser aplicados en creaciones artísticas. De esta manera, la reivindicación de la distinción entre ciencia y arte y la aplicación de tecnologías en proyectos artísticos se da por una relación de diálogo y respeto entre ellos, de modo que el producto final pueda ser moldeado para transmitir un mensaje a una sociedad sensible con parámetros éticos, políticos y de participación.

Cada una de estas manifestaciones se convierte en un medio para comunicar algo más allá de lo común, es decir, para abrir el arte a nuevos significados. El fin del arte es transmitir y provocar fruición en el espectador; para ello, el artista innova cada vez más en nuevas formas, métodos, herramientas, técnicas de representación y materiales, siendo el espectador quien puede aceptar o rechazar estas manifestaciones. Para este tipo de representaciones artísticas, primero, se deben romper los viejos esquemas de lo que se considera como arte y abrir la posibilidad a nuevas formas de representación. Una forma de mostrar el arte pueden ser los paradigmas del cuerpo humano, las metáforas en las cuales se pretende dar un mensaje no directo, y, para ello, la creatividad tiene un campo aún por descubrir, al momento de escoger materiales, lienzo, pieles artificiales, texturas y colores que también van a contribuir a dar a la piel -como motivo- nuevas formas de expresión.

La intención, en esta propuesta, se ha centrado en comprender la piel como agente e intersección de lo biológico, lo psicológico y lo social, lo cual resulta importante para determinar las relaciones entre sujeto y sociedad. Además, se ha buscado establecer la valoración de la piel, comenzando por elaborar su significado más amplio para después experimentar con la elaboración de un símil en el laboratorio y, finalmente, alcanzar una etapa de representación de heridas, cicatrices y marcas, las cuales encuentran un significado a partir de la memoria corporal. De esta manera, la representación de la piel, mediante una propuesta que implica el uso de materiales biológicos con fines artísticos, nos sitúa ante la posibilidad de concebir el bioarte como principio dinámico de significados, de darle nuevas aplicaciones en el ámbito de la pintura y escultura y también de crear espacios participativos de reflexión en los cuales construir un discurso crítico, así como los preceptos en los cuales basamos nuestro conocimiento. 


\section{Referencias}

AAL (2016, 27 de agosto). El arte transhumano de Stelarc. Arte Al Límite (sitio web). Recuperado de https://www.arteallimite.com/2016/08/arte-transhumano-sterlac/.

Benítez, L. (2013). Bioarte. Una estética de desorganización. Barcelona: Universidad Autónoma de Barcelona. Tesis Doctoral. Recuperado de http://www. tdx.cat/bitstream/handle/10803/129126/lbv1de1.pdf?sequence=1

Carreño Pineda, L. D.; Caicedo Mesa, L. A.; Martínez Riascos, C. A. (2012). Técnicas de fermentación y aplicaciones de la celulosa bacteriana. Ingeniería y Ciencia, 8(16). Colombia: Universidad EAFIT, 307-335.

De Certeau, M. (1997). La historia: entre el decir y el hacer. Buenos Aires: Nueva Visión.

Douglas, A. E, (2010). The symbiotic habit. New Jersey, EEUU: Princeton University Press.

Esparza, G. (2015). Cultivos. México: Conaculta / Dirección General de Publicaciones.

Heidegger, M. (1999). Ser y tiempo. Madrid: Trota.

Kac, E. (2010). Telepresencia y Bioarte: Interconexión en red de humanos, robots y conejos.Murcia: CENDEAC.

Lattanzi, J. (2013). ¿El poder de las nuevas tecnologías o las nuevas tecnologías y el poder? Cuadernos del Centro de Estudios en Diseño y Comunicación, XIII, 45, 15-25. Recuperado de http://www.scielo.org.ar/pdf/ccedce/n45/ n45a02.pdf.

Martínez, C. (2009). Diagnóstico del proceso de teñido con añil y propuesta de teñido orgánico. El Salvador: Universidad Centroamericana "José Simeón Cañas".

Martínez, S. (2011). La piel como superficie simbólica. Madrid: FCE.

Mejía, I. (2005). El cuerpo post-humano. México: UNAM.

Pane, G. (2003). Carta a un desconocido. París: Escuela Nacional de Bellas Artes.

Quintais, L. (2009). A través de un nombre: sobre Retrato proteico, de Marta Menezes. En: Menezes, M. et al. Marta Menezes. Retrato Proteico. Badajoz: MEIAC, 93-101.

Rincón, D. L.; Cirlot, L. (2013). Historiando el bioarte o los retos metodológicos de la Historia del Arte (de los medios). Artnodes. Revista de arte, ciencia y tecnología, (13). 62-71. DOI: http://doi.org/10.7238/a.v0i13.1999.

Salgado, S. (2012). La Filosofía de Aristóteles. Cuadernos Duererías, Serie Historia de la Filosofía 12, 1-68. Recuperado de http://guindo.pntic.mec.es/ ssag0007/filosofica/aristoteles-duererias.pdf. 